\title{
Assessing Cause and Effect in Supply Chain Problems Using Sports Ranking Models
}

\author{
Don N. Pope \\ College of Business Administration \\ Abilene Christian University, Abilene, Texas 79699 \\ Email:don.pope@coba.acu.edu
}

\begin{abstract}
Supply chain problems are complex to understand and solve because of the interaction between multiple factors within and between tiers of the chain. Causal factors in business process deficiencies can be thought of as networks of factors, each of which has possible cause-effect relationship with selected other factors. The full significance of any given factor cannot be understood by evaluating just direct relationships between factors, but must be evaluated considering the total direct and indirect influences throughout the entire network of causal linkages. Because of their applicability to such general networks of relationships, sports ranking methodologies have application to cause-effect analysis. Three different matrixbased sports ranking methodologies are discussed and applied to quality cause-effect analysis: Google PageRank, Colley and Massey methods. Of these three, the PageRank and Massey methods are shown to be reasonable approaches in this application context, depending on the causal data available. All the methods are intuitive to apply and compute with spreadsheets.
\end{abstract}

Keywords: quality management, quality tools, cause and effect analysis, sports ranking models, supply chain management

\section{INTRODUCTION}

This paper brings together concepts from two different areas, cause-effect analysis in quality management, and sports ranking models. One should understand that "quality management" applies to all business processes and factors having a bearing on customer requirements and satisfaction, and not just the elimination of manufacturing defects. This broad view would include inventory management issues, financial process problems, human resource concerns, and others.

\subsection{Quality Management Cause-Effect Analysis}

The determination and correction of root causes of process variation is one of the key principles in quality management. (Note that the literature of quality management is much more prone to use the term "cause" in discussing the relationship between factors as opposed to statisticians who avoid the term "cause" but instead prefer the term "correlation".) The identification of root causes is foundational in the teachings of Deming and Juran and in ISO 9000 and Six Sigma (Ashok et al., 2013; Cudney and Agustiady, 2017; De Mast and Lokkerbol, 2012; Garvin, 1986; Montgomery and Woodall, 2008; Yahya and Goh,
2001). The American Society for Quality (ASQ, 2018) and the Union of Japanese Scientists and Engineers (JUSE, 2019) provide examples of various "quality tools" which are intended to spur conversation and understanding of possible causes of quality concerns. Gustafsson (1997) overviews the origins of these quality tools, with much of the credit for developing these toolboxes going to the Union of Japanese Scientists and Engineers (JUSE, 2019). The first toolbox was called the seven quality control tools (Q7 or 7 QC-tools) (Ishikawa, 1982). The next toolbox was the seven management tools (N7 or 7 M-tools) (JUSE, 2019; Mizuno, 1988). The latest development was the seven product planning tools (7 PP-tools) (Kanda, 1994). Among such quality tools are Pareto charts, the Ishakawa "fishbone" chart (Ishakawa , 1982,1985), the failure modes and effects (FMEA) chart (Dhillon, 1992), the "five why" process for drilling down to root causes, and others.

Some tools are purely visual and conversational in nature, while others attempt to quantify the impact and relative importance of causal factors. FMEA summarizes the impact of causes of some issue based on probability of occurrence, impact of occurrence, and ease of detection. Cause-effect (CE) matrices, also known as XY matrices, attempt to quantify the relative influence of factors in a general network of causal linkages (Six Sigma Development Solutions, 2018). Quality function deployment (QFD) diagrams map the strength of relationships of a set of inputs relative to a set of prioritized outputs and thereby rank the significance of the inputs on the given set of outputs (Chan and Wu, 2002; Mizuno, 1994). Statistical techniques such as regression, factor analysis and structural equation modeling are also utilized to quantify possible relationships between various factors, as well as Goldratt's Current Reality Tree method (Dettmer, 1997), Root Cause Analysis (Rooney and Vanden Heuvel, 2004), and Analytical Hierarchical Planning (AHP) (Saaty, 1990; Vaidya and Kumar, 2006). Another broad body of literature sometimes applied in root cause analysis is multiple criteria decision making (MCDM). Mardani et al. (2015) provide a broad survey of MCDM applications and Senthikannan and Parameshwaran (2019) demonstrate a specific application example in the Indian paper industry. Yet another widely used approach, as exemplified by Assaf and Al-Hejji (2006) and Sambasivan and Soon (2007) in the construction industry, is the survey of subject matter experts and computing the weighted importance of various possible causal factors based on expert judgement. 
The sports ranking models proposed to be applied here are advantageous because their assumed structure is more directly applicable to the total network of causal relationships than that of QFD, FMEA, and AHP-based methods. The sports models consider the entire network of causal linkages, all at once and no particular hierarchy or structure of the network of linkages is assumed. The sports ranking methods have the added advantage of having been validated more than many proposed industrial applications. Playoff results in sports provide the means to test and validate the ranking methodologies computed prior to the playoffs. Finally, all of the sports ranking methods presented here are easily implementable using the matrix functions in spreadsheets.

\subsection{Matrix-Based Sports Ratings/Rankings Methods}

Some sports ratings/rankings models are regression models while others are based on matrices of outcomes of games between various teams. For our purposes, the matrixbased methods are of interest, and one widely used approach is the Google PageRank (GPR) algorithm. See Bryan and Leise (2009) for a thorough explanation of the theoretical mathematical foundation for the PageRank algorithm. Gleich (2015) reviews the breadth of application of PageRank in various fields including neuroscience, engineering, literature, medicine, and others. Some researchers have applied the PageRank algorithm to develop sports ratings of individuals or teams and predict winners. Well before the advent of Google and the PageRank algorithm, Keener (1993) described the uses of the principal eigenvector of a matrix of relative strength between teams and tested the approach using the 1989 NCAA football season results. Govan, Meyer and Albright (2008) and Zack, Lamb and Ball (2012) apply PageRank-based models to ranking NFL teams. Mattingly and Murphy (2010) propose a Markov method similar in structure to PageRank to rank not only individual teams, but also the relative strengths of conferences. Beggs et al. (2017) use GPR to assess the relative performance of track athletes.

In contrast to the iterative eigenvalue-based approach of GPR, other matrix-based methods seek to solve systems of equations that reflect the relative strengths of teams based on game outcomes. One such method, the Colley Method (2002), was proposed as a conceptually simple bias-free matrix method of comparing sports teams based simply on the number of wins and losses. The margins of victory or defeat, and the specific opponents played, are ignored to maintain simplicity and avoid the artificial effects of a "blow out" win or loss margin as well as perceived "upsets". The Massey method (1997) is similar to the Colley Method except that the collective total margins of victory and defeat are considered. Refer to Chartier et al. $(2011,2011)$ and Langville and Meyer (2012) for discussions of the application of these methods.
The GPR and Massey methods both consider the game score margins while the Colley method does not. The essential difference between GPR versus the Colley and Massey methods is that GPR includes the "ripple effect" of a team's performance versus opponent $\mathrm{x}$ and, in turn, opponent x's performance against other teams, etc. The Massey method only considers overall season total points for and against and thus omits the ripple effect created by considering strengths of opponents. GPR has been criticized, however, because the rating of every team affects the ratings of many other teams, and the results of an "upset" game over a given weekend can significantly affect many team rankings the following Monday morning (Chartier et al., 2011). The fact that the Colley and Massey methods ignore the outcomes of specific pairings of opponents makes them more stable and less sensitive to upsets than PageRank.

\section{APPLICATION OF GOOGLE PAGERANK, COLLEY AND MASSEY METHODS TO CAUSE- EFFECT ANALYSIS}

Let us now illustrate and compare the use of these sports rating/ranking methods for cause-effect analysis purposes, first for a very simple manufacturing problem, then for a more complex analysis of why college students might fail a test. The sports ranking models are applied in this paper because of their direct applicability to the relations diagram, also known as an interrelationship digraph or network diagram (American Society for Quality, 2018; Gustafsson, 1997; JUSE, 2019; Mizuno, 1994; Tague, 2004). This particular quality tool shows possible cause-effect relationships as a network of linkages among a set of factors. Figure 1 is an actual instance of this methodology applied to analyzing possible causes of excessive overtime in the machine shop of an aircraft fabrication factory. These diagrams are important because they allow more general interlinking between factors than the one-way branching in tree diagrams or fishbone charts and can have bidirectional causal relationships as well as feedback loops.

The traditional approach outlined in the quality management literature to rank the causal significance of the various factors is to count the arrows in and out of each factor. Factors with many arrows in and or out are deemed worthy of special attention. Factors with more outgoing arrows than incoming arrows are deemed to be important causes, while factors with more incoming arrows than outgoing are deemed to be important effects. Such an approach is obviously simplistic and ignores the relative magnitude of the causal relationships, as well as total direct and indirect impacts versus only direct causal impacts. For example, if factor $\mathrm{X}$ is a cause of $\mathrm{Y}$ and $\mathrm{Y}$ is, in turn, a cause of $Z$, then $X$ 's overall significance as a causal factor should be derived from its direct impact on $\mathrm{Y}$ and also its indirect impact on $\mathrm{Z}$. 


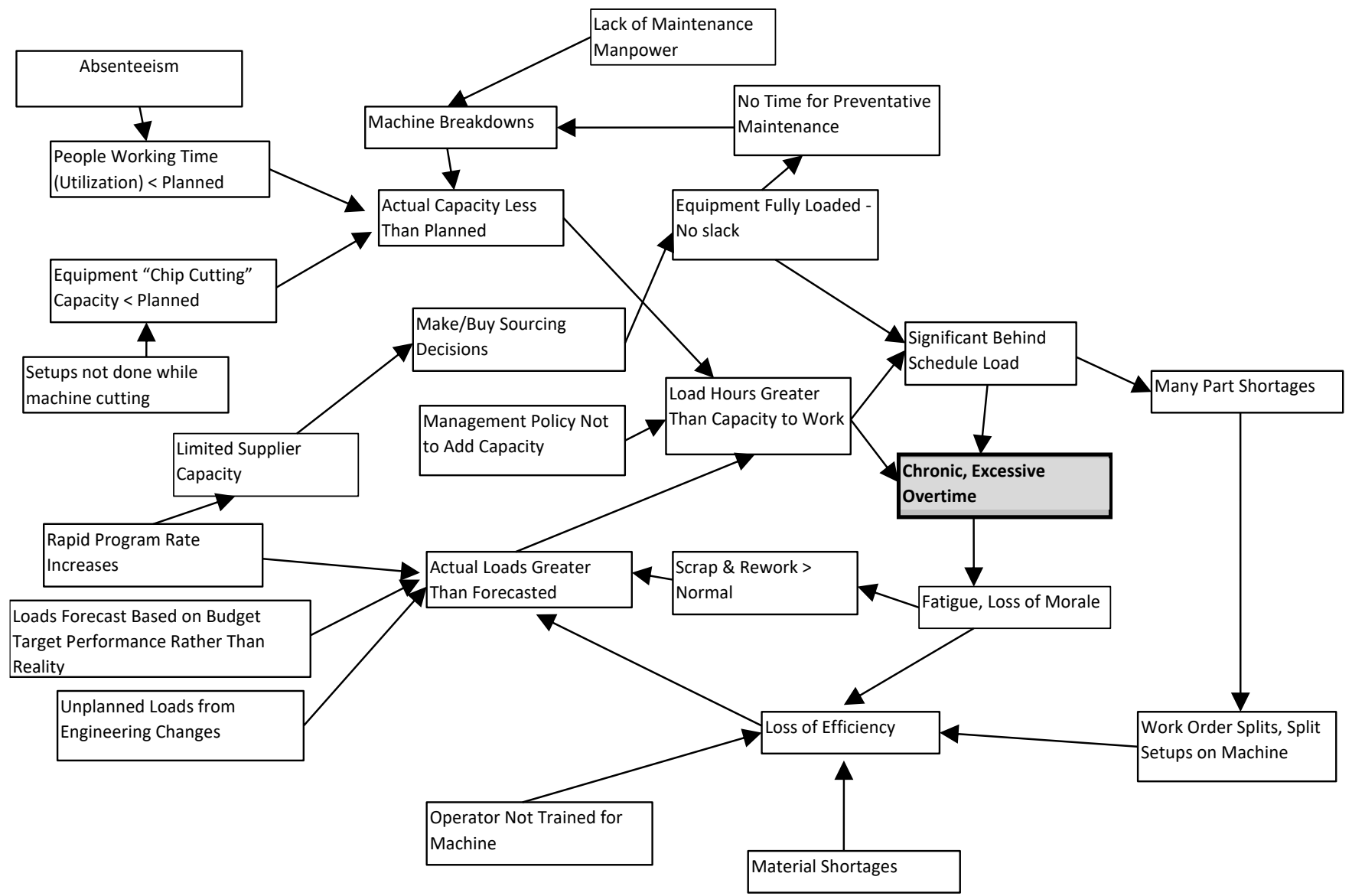

Figure 1 Cause-effect relations diagram from aircraft manufacturing

\subsection{Idealized Example Causal Diagram of Manufacturing Problems}

Figure 2 illustrates an idealized manufacturing example to explore the magnitude of causal impacts on the ultimate effect, unhappy customers. (Note that beyond this simple example, the proposed ranking methods apply to more general networks having bidirectional causal relationships as well as feedback loops.) In this example, the factors (nodes) of sloppy workmanship, bad engineering, and defective parts ultimately trace their causes back through each other to the ultimate "other causes" outside the scope boundary of the analysis. The numbers on each arrow from factor $\mathrm{x}$ to factor $\mathrm{y}$ indicate that factor $\mathrm{x}$ accounts for that portion of the reasons why factor $y$ occurs. The total of the incoming arrows into any factor y should equal 1.0. The factor with only incoming causes and no outgoing effects is the ultimate effect of interest in the model. This example is idealized, for comparative purposes, in that one factor node has 4 causal inputs of equal impact and no outputs, one node has 3 causal inputs of equal impact and 1 output, one node has 2 causal inputs and 2 outputs, etc.

So what is the analogy between cause-effect relationships between various factors and the outcomes of sports events? We assume that if factor $\mathrm{x}$ comprises .2 of the causal effect on factor $y$, then factor $x$ "wins a game" against factor $y$ by a score margin of .2 to 0 . Thus the number of "wins" for factor $\mathrm{x}$ is the number of causal relationships that factor $x$ has upon other factors. And, the number of "defeats" for factor $\mathrm{x}$ is the number of incoming causal relationships from other factors. If there is no causal link between two factor nodes, then their "game" is assumed to be a scoreless tie.

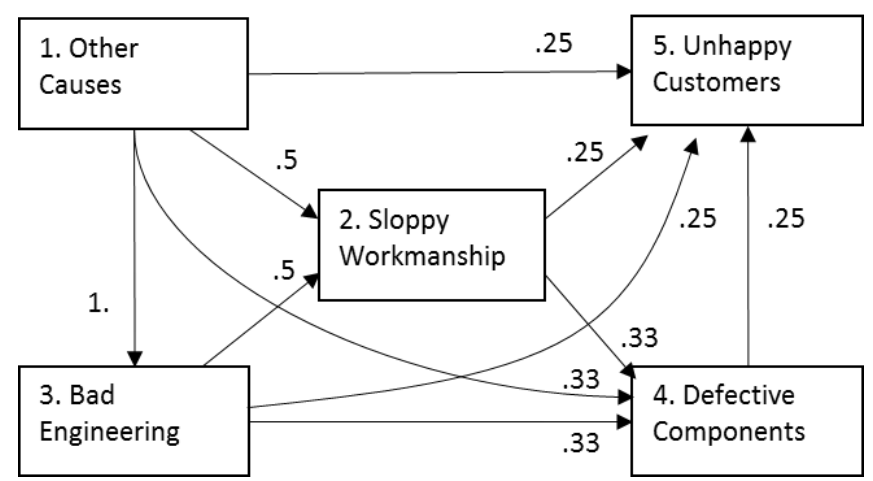

Figure 2 Idealized example causal diagram of manufacturing problems

\subsection{Google PageRank}

The relative importance ratings of each node of a network (sports teams, for example) are computed as elements of the left principal eigenvector of a matrix $G$ which is computed as a weighted sum of 2 other matrices, $S$ and $E$. Specifically,

$\mathrm{G}=\alpha \mathrm{S}+(1-\alpha) \mathrm{E}$, with $0 \leq \alpha \leq 1$.

Matrices $\mathrm{G}, \mathrm{S}$ and $\mathrm{E}$ are all square $\mathrm{n} \mathrm{x}$ n matrices where each row and column represent a team in the set of $n$ teams being compared. Matrix $\mathrm{S}$ is a row-stochastic matrix derived from a matrix $M$ which captures relative strength relationships between each pair of teams, based on the score 
outcomes of previous games. Matrix E represents the "on any given day..." effect that recognizes that other factors also affect the outcomes of past and future games between these two teams. The elements of $\mathrm{E}$ are all 1/n. The choice of the weighting factor $\alpha$ simply gives more or less weight to the relationship matrix $\mathrm{S}$, based on previous game score outcomes, and the "all other considerations" matrix E. Google selected an $\alpha$ value of .85 for rating web sites.

The page ranks (which we will call the rating vector $\vec{r}$, the relative dominance ratings of the teams), are then computed as the dominant left eigenvector of matrix G. We will use the term "ratings" to designate the computed relative strengths of the teams, and "rankings" to refer to the final $1,2,3, \ldots$ sequential rankings of the teams based on their computed ratings. One method of computing this rating eigenvector $\vec{r}$ is through several iterations of the equation:

$$
\vec{r}^{\mathrm{i}}=\vec{r}^{\mathrm{i}-1} \mathrm{G},
$$

where $i$ is the iteration number. In the context of the causeeffect example in Figure 2, Table 1 summarizes the G matrix of magnitude of the effects from and to each factor (node) in the diagram. For computational purposes, the element $\mathrm{G}_{5,5}$ in the matrix is set $=1.0$. Since the "other causes" factor is explicitly considered in our example, the E matrix of equation (1) is omitted. Table 2 shows the results of 3 iterations of equation (2). The interpretation of the results is that given a relative importance rating of 100 for the ultimate effect (Factor 5 unhappy customers), then factor 4 (defective components $)=.25 * 100=25$. Factor 2 (sloppy workmanship) $=.25 *$ Factor $5+.33 *$ Factor $4=.25 * 100+$ $.33 * 25=33.33$. Factor 3 (bad engineering) $=.25 *$ Factor $1+$ $.33 *$ Factor $4+.5 *$ Factor $2=50$. Everything links back to the ultimate other causes which always has the same total rating as the ultimate effects, $1 . * 50+.5 * 33.33+.33 * 25+$ $.25 * 100=100$

If we focus on the relative magnitudes of factors 2 through 4 and omit the ultimate effect (factor 5) and other causes (factor 1), then their relative magnitudes are $.308, .461, .231$.

\subsection{Colley Method}

In the Colley Method, the rating vector $\vec{r}$ is the solution of this system:
$\mathrm{C} \vec{r}=\vec{b}$

where $b_{i}=1+$ (number of wins for team $i$ - number of losses for team i) $/ 2, C_{i i}=2+$ number of games that team i played, and $C_{i j}=-n_{i j}$ where $n_{i j}$ is number of games played between teams $i$ and $j$. The $b_{i}$ values are computed for Figure 2 in Table 3.

The solution vector $\vec{r}$ is $(.786, .5, .643, .357, .214)$. As we did with the GPR results, computing the normalized relative magnitudes of factors 2 through 4 , the results are $.333, .428, .238$.

Table 1 Matrix G of effects from and to each factor (node)

\begin{tabular}{|c|c|c|c|c|c|c|}
\hline & \multicolumn{5}{|c|}{ From Node } \\
\hline & & 1 & 2 & 3 & 4 & 5 \\
\hline \multirow{5}{*}{$\begin{array}{l}\frac{0}{0} \\
\text { 은 } \\
ㅇ\end{array}$} & 1 & 0 & 0 & 0 & 0 & 0 \\
\hline & 2 & 0.5 & 0 & 0.5 & 0 & 0 \\
\hline & 3 & 1.0 & 0 & 0 & 0 & 0 \\
\hline & 4 & 0.333 & 0.333 & 0.333 & 0 & 0 \\
\hline & 5 & 0.25 & 0.25 & 0.25 & 0.25 & 1.0 \\
\hline
\end{tabular}

Table 2 Results of iterations of computing the left eigenvector of matrix $\mathrm{G}$

\begin{tabular}{|l|l|l|l|l|l|}
\cline { 2 - 6 } \multicolumn{1}{c|}{} & \multicolumn{5}{c|}{ Node } \\
\cline { 2 - 6 } \multicolumn{1}{c|}{} & $\mathbf{1}$ & $\mathbf{2}$ & $\mathbf{3}$ & $\mathbf{4}$ & $\mathbf{5}$ \\
\hline Starting Ratings & 0 & 0 & 0 & 0 & 100 \\
\hline Iteration 1 & 25 & 25 & 25 & 25 & 100 \\
\hline Iteration 2 & 70.8 & 33.3 & 45.8 & 25 & 100 \\
\hline Iteration 3 & 95.8 & 33.3 & 49.99 & 25 & 100 \\
\hline Iteration 4 & 99.99 & 33.3 & 49.99 & 25 & 100 \\
\hline
\end{tabular}

Table 3 Colley $\mathrm{C}$ matrix and $\mathrm{b}$ vector

\begin{tabular}{|c|c|c|c|c|c|}
\hline Node & $\mathbf{1}$ & $\mathbf{2}$ & $\mathbf{3}$ & $\mathbf{4}$ & $\mathbf{5}$ \\
\hline $\mathbf{1}$ & 6 & -1 & -1 & -1 & -1 \\
\hline $\mathbf{2}$ & -1 & 6 & -1 & -1 & -1 \\
\hline $\mathbf{3}$ & -1 & -1 & 6 & -1 & -1 \\
\hline $\mathbf{4}$ & -1 & -1 & -1 & 6 & -1 \\
\hline $\mathbf{5}$ & -1 & -1 & -1 & -1 & 6 \\
\hline
\end{tabular}

Table 4 Translation of cause-effect linkages into sports wins/losses and scores

\begin{tabular}{|c|c|}
\hline Node & $\begin{array}{c}\text { Games } \\
\text { Played, } \\
\text { Including } \\
\text { Scoreless Ties }\end{array}$ \\
\hline 1 & 4 \\
\hline $\mathbf{2}$ & 4 \\
\hline 3 & 4 \\
\hline 4 & 4 \\
\hline 5 & 4 \\
\hline
\end{tabular}

\section{Used in Colley Method}

\begin{tabular}{|c|c|c|}
\hline $\begin{array}{c}\text { Number of } \\
\text { Incoming } \\
\text { Causes } \\
\text { (Losses) }\end{array}$ & $\begin{array}{c}\text { Number of } \\
\text { outgoing } \\
\text { effects } \\
\text { (Wins) }\end{array}$ & $\begin{array}{c}\mathrm{b}_{\mathrm{i}}=1+ \\
\text { (Number of } \\
\text { Wins - } \\
\text { Number of } \\
\text { Losses)/2 }\end{array}$ \\
\hline 0 & 4 & 3 \\
\hline 2 & 2 & 1 \\
\hline 1 & 3 & 2 \\
\hline 3 & 1 & 0 \\
\hline 4 & 0 & -1 \\
\hline
\end{tabular}

\begin{tabular}{|c|c|c|}
\hline \multicolumn{3}{|c|}{ Used in Massey Method } \\
\hline $\begin{array}{c}\text { Total of } \\
\text { Incoming } \\
\text { Causes } \\
\text { (Total Points } \\
\text { Against) }\end{array}$ & $\begin{array}{c}\text { Total of } \\
\text { Outgoing } \\
\text { Effects } \\
\text { (Total Points } \\
\text { Scored) }\end{array}$ & $\begin{array}{c}\mathrm{p}_{\mathrm{i}}= \\
\text { Score } \\
\text { Margins } \\
\text { (Points } \\
\text { Scored - } \\
\text { Points } \\
\text { Against) }\end{array}$ \\
\hline 0 & 2.08 & 2.08 \\
\hline 1 & .583 & -0.417 \\
\hline 1 & 1.083 & 0.083 \\
\hline 1 & .25 & -0.75 \\
\hline 1 & 0 & -1 \\
\hline
\end{tabular}




\subsection{Massey Method}

The rating vector $\vec{r}$ is the solution of this system:

$\mathrm{M} \vec{r}=\vec{p}$

where $\mathrm{M}_{\mathrm{ii}}=$ number of games played by team $\mathrm{i}$ and $\mathrm{M}_{\mathrm{ij}}=$ number of games between teams $i$ and $j$. Note that $M$ is related to the Colley matrix $\mathrm{C}$ by $\mathrm{M}=\mathrm{C}-2 \mathrm{I}$. The vector $\vec{p}$ is a vector of season cumulative point differentials, that is, $\mathrm{p}_{\mathrm{i}}$ is the total points scored by team i against all opponents - the total points scored by all opponents against team i, as shown in Table 3. The system $\mathbf{M} \vec{r}=\vec{p}$ is singular, so typically, users have arbitrarily set the last row of elements in $\mathrm{M}$ to be all 1 , and the last element in the $\vec{p}$ vector is set $=0$.

Table 5 Massey $M$ matrix and $\mathrm{p}$ vector, with the last row of $\mathrm{M}$ set to 1 and $\mathrm{p} 5$ set to 0 .

\begin{tabular}{|c|c|c|c|c|c|}
\hline Node & $\mathbf{1}$ & $\mathbf{2}$ & $\mathbf{3}$ & $\mathbf{4}$ & $\mathbf{5}$ \\
\hline $\mathbf{1}$ & 4 & -1 & -1 & -1 & -1 \\
\hline $\mathbf{2}$ & -1 & 4 & -1 & -1 & -1 \\
\hline $\mathbf{3}$ & -1 & -1 & 4 & -1 & -1 \\
\hline $\mathbf{4}$ & -1 & -1 & -1 & 4 & -1 \\
\hline $\mathbf{5}$ & 1 & 1 & 1 & 1 & 1 \\
\hline
\end{tabular}

The solution vector $\vec{r}$ is $(.417,-.083, .017,-.15,-.2)$. Again, we compute the relative magnitude of the ratings of factors 2 through 4 to be $(.3, .57, .13)$.

\section{COMPARISON OF THE RESULTS OF THE METHODS}

Table 6 provides a summary comparison of the three method's ratings for this idealized example. The ultimate other causes factor and the ultimate effect are both omitted and the focus is on the other factors. Let us first consider the relative ratings implicit in the traditional quality management approach of simply counting input arrows versus output, and those with the most outgoing causal arrows compared to incoming would be deemed the most significant causes. So, for factor 2 , the ratio of outgoing arrows to incoming is $2 / 2=1.0$. For factor 3 the ratio is $3 / 1$ $=3.0$. For factor, the ratio is $1 / 3=.33$. So normalizing these ratios gives a relative causal significance rating for factors 2 through 4 of $.231, .692, .077$.

Now comparing the relative ratings of factors 2 through 4 for each sports rating method, first note that the Colley method simply considers the number of causal linkages to and from each factor node, regardless of the magnitude of the causal effect, although the Colley algorithm computes different relative ratings than that based simply on the traditional approach of ratios of outgoing arrows versus incoming. Thus, like the traditional method, the Colley method does not really accomplish our objective of considering the strength of direct causal relationships in computing the overall causal significance of the factors, given the complete network of relationships.
Thus, we know focus on GPR and the Massey method. The essential difference between GPR versus Massey is that GPR includes the "ripple effect" of the magnitude of a causal effect of factor $\mathrm{x}$ upon another factor $\mathrm{y}$, and in turn, the magnitude of factor $y$ effects on others, etc. The Massey method only considers overall total of the magnitude of causal linkages into and out of each factor node and thus does not reflect indirect causality ripple effects. Note that in this example, while all the ratings are in the same sequence (Bad Engineering is the most significant causal factor and Defective Components is the least significant), the Colley ratings are closer to each other and thus less differentiated than those of GPR, which in turn is less differentiated from each other than with Massey. The Massey method rates factor 3 (Bad Engineering) very strongly because it had several strong causal outputs on other immediately affected factors. GPR, on the other hand, computes all the net causal effects between all the factors, and thus weights factor 3 less strongly in terms of its impact on the ultimate effect and not just those factors directly impacted by factor 3 .

Table 6 Comparison of results of traditional quality tools output versus input link arrow counting, Google PageRank (GPR), Colley and Massey methods for idealized example

\begin{tabular}{|l|c|c|c|c|}
\cline { 2 - 5 } & \multicolumn{3}{|c|}{ Relative Ratings of Factors 2,3 and 4 } \\
\cline { 2 - 5 } & $\begin{array}{c}\text { Traditional } \\
\text { Output/Input } \\
\text { Links }\end{array}$ & GPR & Colley & Massey \\
\hline $\begin{array}{l}\text { 2. Sloppy } \\
\text { Workmanship }\end{array}$ & .231 & .308 & .333 & .305 \\
\hline $\begin{array}{l}\text { 3. Bad } \\
\text { Engineering }\end{array}$ & .692 & .461 & .428 & .565 \\
\hline $\begin{array}{l}\text { 4. Defective } \\
\text { Components }\end{array}$ & .077 & .231 & .238 & .130 \\
\hline
\end{tabular}

Figure 3 illustrates a more complex example involving hypothetical causal linkages among several factors that could contribute directly or indirectly to a college student's failing a test. Figure 4 summarizes the results of computing factor ratings using the GPR, Colley and Massey methods. The GPR and Massey results tend to be closer to each other than to the Colley results which simply reflects the number of causal linkages into and out of each factor. Since many of the factors had the same number of inputs and outputs, the Colley ratings tended to be very close to each other. GPR and Massey, on the other hand, consider the strength of these relationships and not just the number of inputs and outputs of each factor. The highest rated four factors by GPR were lack of self-discipline, did not study enough, did not understand the lectures, and too much play time. The Massey method also identified the same top four factors, albeit in this sequence: lack of self-discipline, too much play time, did not study enough, and did not understand the lectures. Note that this example, like the earlier idealized example, also exhibits the more strongly differentiated ratings of the Massey method as compared to the other two methods. 


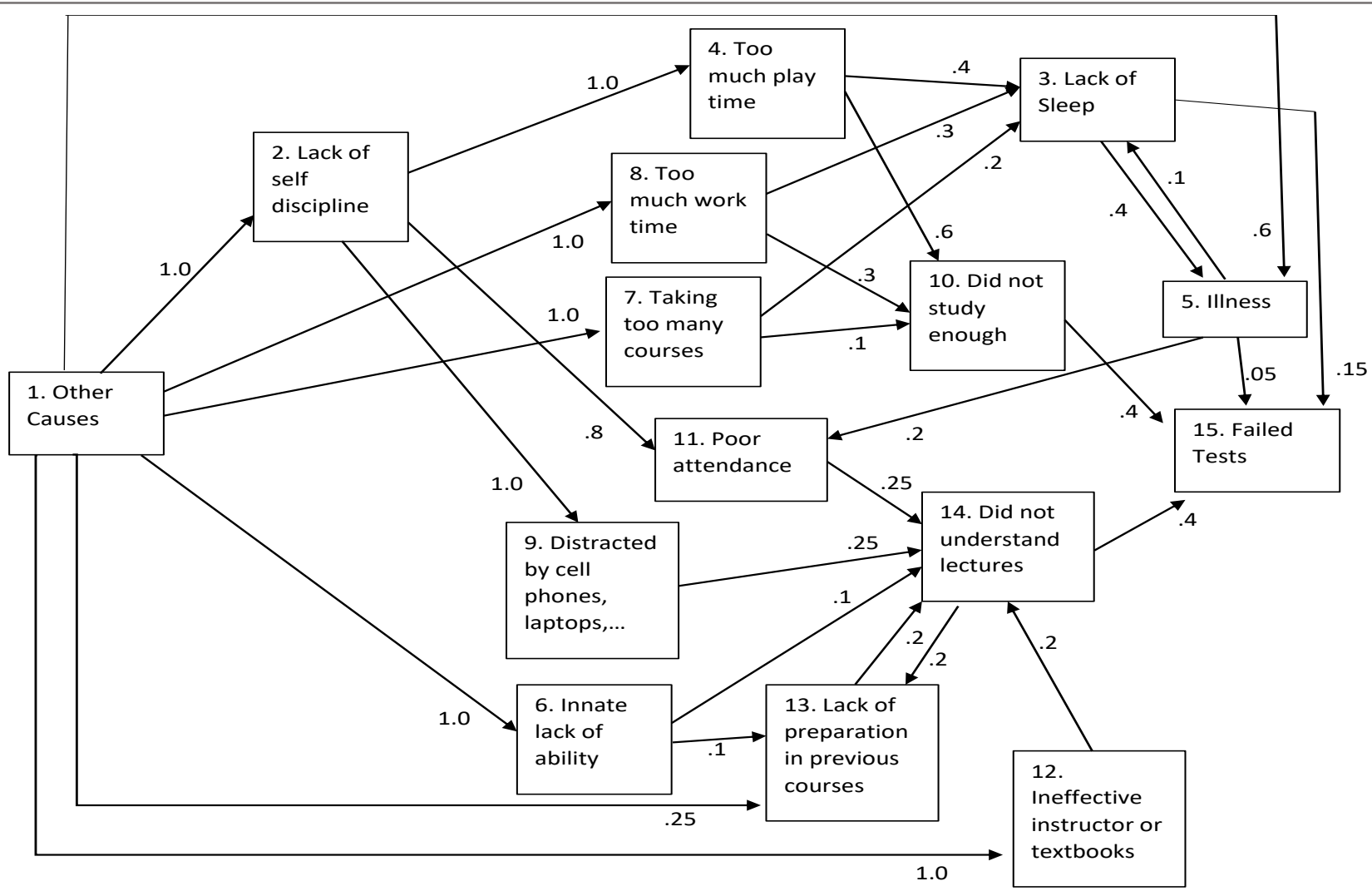

Figure 3 Causal diagram of college student test failure

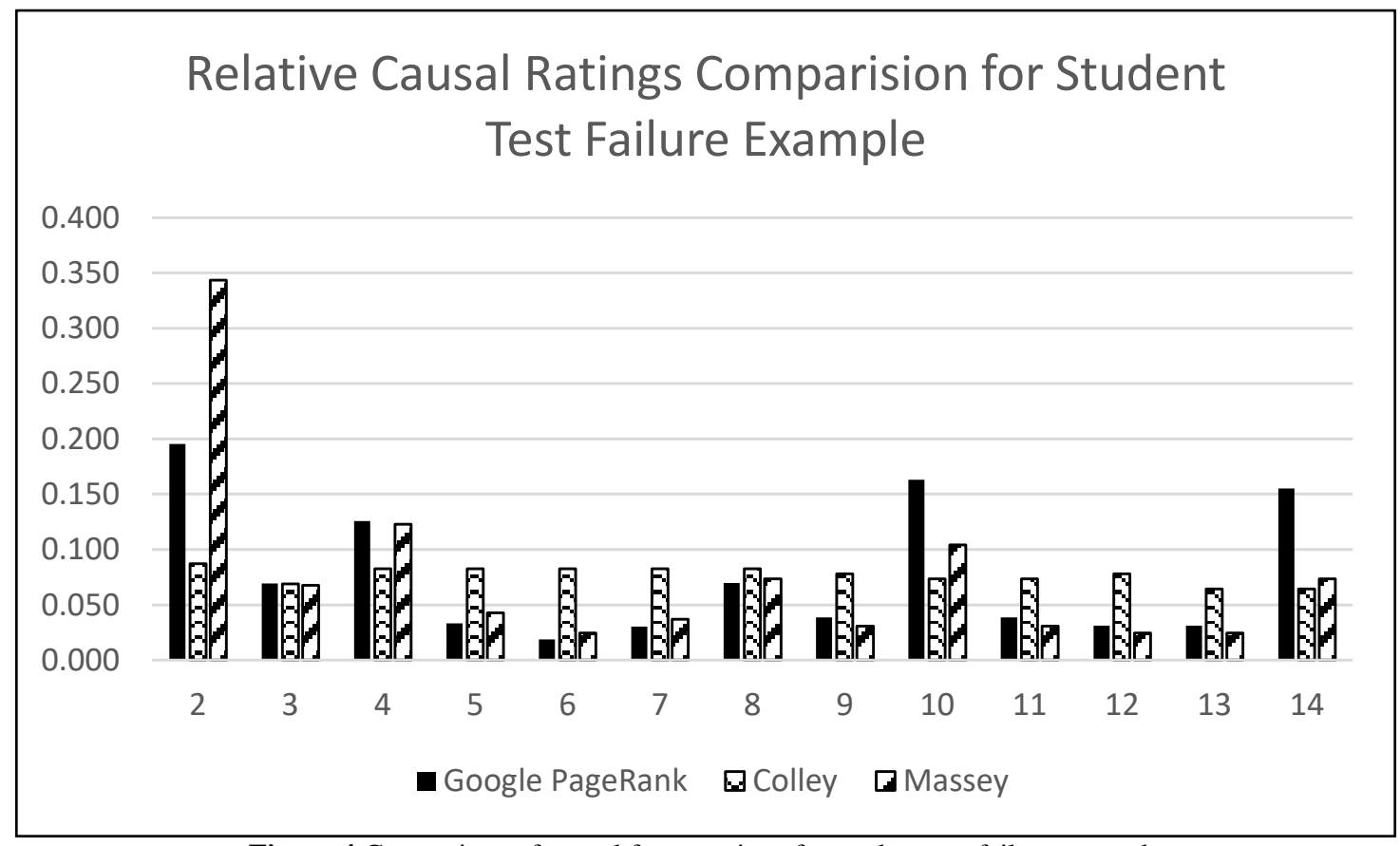

Figure 4 Comparison of causal factor ratings for student test failure example

\section{CONCLUSIONS}

The matrix-based sports ranking models are applied in this paper because of their direct applicability to one of the widely used quality tools, the relations diagram, and its general network structure. The sports ranking models provide a method for quantifying the significance of each causal factor. The simplest of these, the Colley method, only considers the number of causal linkages to and from each factor node, regardless of the magnitude of the causal effect linkage. Another issue with the Colley method (or any method that simply counts incoming versus outgoing causal links) is that the inclusion of trivial causal linkages would significantly affect the ratings based this method.

As seen in the second example about test failures, the Google PageRank method and the Massey method yielded similar overall results. The essential difference between PageRank versus Massey is that Google PageRank more 
explicitly includes the "ripple effect" of the magnitude of a causal effect of factor $\mathrm{x}$ upon another factor $\mathrm{y}$, and in turn, the magnitude of factor $y$ effects on others, etc. The Massey method only considers overall total of the magnitude of causal linkages into and out of each factor node and thus does not reflect ripple effects. However, one could possibly argue the merits of either approach. If one were confident of estimates of the magnitude of the causal linkages in a real world application, then the PageRank method would capture both the direct and indirect secondary causal relationships to help the quality assessment team fully appreciate the overall significance of various factors on the ultimate effect of interest. If, however, the causal linkage data were deemed to be rough estimates at best, then the ripple effect inherent in the PageRank method would tend to propagate the effects of inaccurate causal perceptions, and the Massey method might be preferable.

Spreadsheet solutions to these example problems are available from the author upon request.

\section{REFERENCES}

American Society for Quality (2018), Learn About Quality. http://asq.org/learn-about-quality/quality-tools.html and http://asq.org/learn-about-quality/new-managementplanning-tools/overview/relations-diagram.html, as accessed 6-5-2018.

Ashok Sarkar, S., Ranjan Mukhopadhyay, A., and Ghosh, S. K. (2013), Root Cause Analysis, Lean Six Sigma and Test of Hypothesis. The TQM Journal, 25(2), 170-185.

Assaf, S. and Al-Hejji, S. (2006), Causes of Delay in Large Construction Projects, International Journal of Project Management, 24, pp. 349-357.

Beggs, C.B., Shepherd, S.J., Emmonds, S. and Jones, B. (2017), A Novel Application of Pagerank and User Preference Algorithms for Assessing the Relative Performance of Track Athletes in Competition, PloS one, 12(6), p.e0178458.

Bryan, K. and Leise, T. (2009), The Linear Algebra behind Google, SIAM Review, 3(3), p. 13.

Chan, L. K., and Wu, M. L. (2002), Quality Function Deployment: A Literature Review, European Journal of Operational Research, 143(3), 463-497.

Chartier T., Kreutzer, E., Langville, A. and Pedings, K. (2011), Sensitivity and Stability of ranking vectors, SIAM Journal of Scientific Computing, 33(3), pp. 1077-1102.

Chartier, T., Kreutzer, E., Langville, A. and Pedings, K. (2011), Sports Rankings with Non-Uniform Weighting, Journal of Quantitative Analysis of Sports 7(3), article 6.

Colley, W.N. (2002), Colley's Bias Free College Football Ranking Method: The Colley Matrix Explained, Princeton, NJ: Princeton University, www.colleyrankings.com.

Cudney, E.A. and Agustiady, T.K. (2017), Design for Six Sigma, CRC Press, Taylor \& Francis Group, Boca Raton, FL.

De Mast, J., and Lokkerbol, J. (2012), An Analysis of the Six Sigma DMAIC Method from the Perspective of Problem Solving, International Journal of Production Economics, 139(2), 604-614.

Dettmer, H. W. (1997), Goldratt's Theory of Constraints: A Systems Approach to Continuous Improvement, ASQ Quality Press, Milwaukee, WI

Dhillon, B. S. (1992). Failure Modes and Effects AnalysisBibliography, Microelectronics Reliability, 32(5), 719-731.

Garvin, D. A. (1986), A Note on Quality: The Views of Deming, Juran, and Crosby, Harvard Business School Background Note 687-011, September 1986. (Revised February 1990.)
Gleich, D.F. (2015), PageRank beyond the Web. SIAM Review, 57(3), pp. 321-363.

Govan, A.Y., Meyer, C.D. and Albright, R. (2008), Generalizing Google's PageRank to Rank National Football League Teams, North Carolina State University, SAS Institute Inc, NC.

Gustafsson, A. (1997), The New Quality Tools, Total Quality Management, 8(3), pp. 167-172.

Ishikawa, K. (1982), Guide to Quality Control, Asian Productivity Press, Tokyo.

Ishikawa, K. (1985), What Is Total Quality Control? The Japanese Way, translated by Lu, D., Prentice-Hall.

JUSE Union of Japanese Scientists and Engineers (2019), http://www.juse.or.jp/english/publications/_as accessed 7-162019.

Kanda, N. (1994), The Seven Product Planning Tools for New Product Development, Hinshitsu Kanri, (45), pp.73-80.

Keener, J. (1993), The Perron-Frobenius Theorem and the Ranking of Football Teams, SIAM Review, 35(1) pp. 80-93.

Langville, A.N. and Meyer, C.D. (2012), Who's \#1: The Science of Rating and Ranking, Princeton University Press, Princeton, NJ.

Mardani, A., Jusoh, A., Nor, K., Khalifah, Z., Zakwan, N. and Valipour, A. (2015), Multiple Criteria Decision-Making Techniques and their Applications - A Review of the Literature from 2000 to 2014. Economic ResearchEkonomska Istraživanja, 28(1), pp.516-571.

Massey, K. (1997), Statistical Models Applied to the Rating of Sports Teams. Honors Thesis, Bluefield College, Bluefield, VA, http:/www.masseyratings.com/theory/massey97.pdf, as accessed 6-5-2018.

Mattingly, R. and Murphy, A. (2010), A Markov Method for Ranking College Football conferences, SUNY Cortland, www.mathaware.org/mam/2010/essays/Mattingly.pdf, as accessed 6-5-2018.

Mizuno, S. (1988), Management for Quality Improvement: The 7 New QC Tools, Productivity Press, Portland, Oregon.

Mizuno, S. (Ed.). (1994), QFD: The customer-driven approach to quality planning and deployment. Asian Productivity Organization.

Montgomery, D.C. and Woodall, W.H. (2008), An Overview of Six Sigma, International Statistical Review, 76(3), pp.329-346.

Rooney, J.J. and Vanden Heuvel, L.N. (2004), Root Cause Analysis for Beginners, Quality Progress, https://servicelink.pinnacol.com/pinnacol_docs/lp/cdrom_w eb/safety/management/accident_investigation/Root_Cause.p df, as accessed 6-5-2018.

Saaty, T.L. (1990), How to make a decision: The Analytic Hierarchy Process, European Journal of Operational Research, 48, pp. 9-26.

Sambasivan, M. and Soon, Y.W., (2007), Causes and Effects of Delays in Malaysian Construction Industry. International Journal of Project Management, 25(5), pp.517-526.

Senthilkannan, N. and Parameshwaran, R. (2019), Performance Analysis and Quality Improvement Using Fuzzy MCDM and Lean Tools in a Paper Industry, International. Journal of Integrated Supply Management, 12(3), pp.205-229.

Six Sigma Development Solutions (2018), https://sixsigmadsi.com/how-to-complete-the-ce-matrix/, as accessed 6-5-2018.

Tague, N.R. (2004), The Quality Toolbox, $2^{\text {nd }}$ edition, ASQ Quality Press, Milwaukee, WI.

Vaidya, O.S. and Kumar, S. (2006), Analytic hierarchy process: An overview of applications, European Journal of Operational Research, 169, pp. 1-29. 
Yahya, S. and Goh, W.K. (2001), The Implementation of an ISO 9000 Quality System, International Journal of Quality \& Reliability Management, 18(9), pp.941-966.
Zack, S., Lamb, L. and Ball, R. (2012), An Application of Google's PageRank to NFL Rankings, INVOLVE, 5(4), pp. 463-471.

Don Pope is Associate Professor of Management at Abilene Christian University, Abilene, Texas. He has a PhD in Industrial Engineering from Texas A\&M University. He had a 20-year career in aircraft manufacturing, working with simulation modeling, manufacturing strategic planning, lean manufacturing and enterprise information systems. He currently teaches operations management, supply chain management, statistics and data analytics. His research interests include supply chain management and applications in humanitarian projects. 